\title{
ON THE (HONEST) TRUTH ABOUT DISHONESTY. HOW WE LIE TO EVERYONE - ESPECIALLY OURSELVES BY DAN ARIELY (2013, LONDON, HARPERCOLLINS)
}

CSONGOR HAJDU ${ }^{l}$

Stating the scientific standpoint that people are not rational may raise challenges, but would not shock many in this era of science. However, arguing that irrationality is logical and consistent might raise attention to this topic of behavioral economics. In this latest book by Dan Ariely, The Honest Truth about Dishonesty, the author continues discussing the topic he started addressing in his earlier book, Predictably Irrational, stating that there is logic and consistency behind 'irrational' human thinking and action. Ariely goes into more detail and narrows down the general topic of irrationality to the topic of cheating, and further, to cheating within an organizational environment.

Dan Ariely is James B. Duke Professor of Psychology and Behavioral Economics at Duke University (North Carolina, USA) and a researcher of behavioral economics. He is the author of several New York Times bestsellers (Predictably Irrational 2008; The Upside of Irrationality 2010), and has given speeches for TED (a global platform for sharing ideas across a variety of disciplines in the form of online conferences) which have been watched by several million viewers.

The core idea of the research described in this book came from the collapse of Enron in 2001. This occurred after the company came crashing down after having significant success on Wall Street through a series of financial tricks, assisted by the board of the company and the accounting agencies it worked closely with. Ariely became interested in whether this collapse was due to a few dishonest and corrupt individuals, or rather to the general blindness of many. The main hypotheses, experiments and findings described in the book are focused on examining where cheating and dishonesty come from, what the human capacity for dishonesty is, and if it is a widespread problem. This book takes the findings of the previous publication to the next level by adding to it practical experience

1 Csongor Hajdu is a $\mathrm{PhD}$ student at the Corvinus University of Budapest, Doctoral School of Sociology. E-mail: csongor.hajdu@yahoo.com 
gained since the former's publication. The book's structure is easy to follow and takes the reader from an overview of the previously described, sometimes general consequences to the point where we can explain, or at least understand, the underlying causes of such significant financial and social phenomena.

Ariely's starting point is that the core element of dishonest behavior - in this case, cheating - involves the battle between two forms of motivation: namely, 'rational' economic motivation which makes people want to cheat, and psychological pressure that motivates people to act in a way that convinces others that they are good. In parallel, he also argues that people are much more moral than they are rational, and that many (surprising) factors can influence decisions about (dis)honesty.

The main perspective that is developed throughout the book starts at the level of the individual and individual-level drivers, then widens in scope to consider the impact of the environment, and ends with a focus on how actions create organizational norms. Ariely starts by describing the model most commonly used to explain rational behavior (cost-benefit analysis) and then disproves the efficiency of this model. He describes several determinants of cheating; firstly, distance from the reward (in the form of the payment vehicle, or as physical distance) and then details how norms should help prevent this type of cheating. His next major argument is that cheating occurs even when individuals have good intentions, and that favors have an impact on unconsciously formed preferences so individuals may not even be aware of them. He notes at this point the theory of rational self-indulgence: in order to avoid depletion of willpower, individuals should succumb to temptation once in a while. Up to this point, his arguments focus on the individual, but then he changes perspective and examines the wider environment and society. He starts this section by describing an experiment which revealed that the perception of individuals in society shapes their actual personalities in a way that fake self-signaling (like the wearing of counterfeit brand apparel) can trigger dishonest action - and more importantly, that such action also makes the individual suspect others of being dishonest. Ariely then expresses his concern about self-deception, which may increase the chance of success but can also be a foundation for a lack of trust and bad decision-making. Another dangerous effect relates to the reasoning and justification behind dishonest acts, which he considers to be an automatic cognitive response. An important finding from Chapter Seven is that creative people cheat more, and not because of their increased propensity to problem-solving, but due to their ability to justify dishonest action. The next perspective he uses widens the scope of the analysis to describe how immoral activities might create general norms, and he warns that cheating can be infectious. Another very interesting finding is that altruism can increase the propensity to cheat, especially when an actor does not 
stand to benefit from such dishonest acts and can maintain a clear conscience. In the closing chapter the author re-emphasizes the inability of the risk-benefit model to explain activity and stresses the need for moral codes and norms.

The book consists of 11 chapters. Ariely starts with an attempt to explain cheating through analyzing Becker's rational cost-benefit analysis model (weighing the risk of being caught against potential penalties and benefits, generalized as the SMORC model - Simple Model of Rational Choice), and highlights why that model fails. He disproves this model through the very first experiment he reviews, which involves a test conducted at MIT (the Michigan Institute of Technology, USA) that paid people based on how many mathematical calculations they performed. The experiment was structured so that either the risk of getting caught could be minimized, or potential benefits increased. Ultimately, quite a few people cheated a lot, but more people cheated only a little, and more importantly, the magnitude of cheating did not change even when potential benefits and/or level of risk was increased.

After disproving the SMORC model, Ariely lists those determinants that seem to be most feasible for explaining cheating based on his experiments. One of the most important such factors was found to be the 'distance' the potential reward is from actual money: experiments suggest that people generally do not hesitate to steal non-monetary objects. For example, an experiment indicated that cheating greatly increased when the reward was not money but something else, even if only slightly different from (or 'away' from) money, such as tokens. The same effect was observed regarding physical distance: for example, in golf people are much more willing to cheat with a club than with part of their body (either hand or foot). At this point Ariely expresses his concern about whether in our current society, which is moving towards having a cashless economy, the morals that help to avoid cheating will be relaxed. What could still support honest behavior is providing people with reminders about standards and norms; this makes them act more ethically (for example, mentioning the Ten Commandments or an honor code, even if the honor code does not even exist). However, long-term honesty cannot be generated even through iterations of such reminders about standards.

From the distance factor, the author moves on to describe moral drivers. Ariely considers cheating to be an activity that can be caused by a conflict of interest, or even through good intentions. What is not that commonly known, but is recognized from experiments, is that owing someone something changes aesthetic preferences. The surprising finding is that this phenomenon is due to generosity or kindness but originates in a deeper part of the brain. This means that favors even influence unconscious behavior. The magnitude of the favors in the experiment influenced individuals' relationships with the benefactor, even as regards largely aesthetic preferences (e.g. preferences for paintings). The author 
considers the results to be shocking, even without consideration of what effect financial and economic lobbying could have on the government in this regard, or medical company representatives on doctors. In the financial sector the effect of financial support (salaries, bonuses, benefits, etc.) can have a crucial effect on employees' opinions about financial activities: these changes in preference may not be noticed by the individuals themselves, but they can nonetheless distort reality, especially in terms of their influence on the subjective interpretation of risks or benefits. Ariely hypothesizes that one solution would be full disclosure, through which consumers would be able to discount opinions and make better decisions. Unfortunately, experiments have indicated that this would do more harm than good: full disclosure creates even more profound effects on those who stand in judgment.

Following the moral perspective, Ariely reviews the theory of "ego depletion" which states that individuals have a limited amount of willpower that they can use to resist temptation. Experiments have shown that when deliberative reasoning ability is saturated, the impulsive system gains more control over behavior. This influences decision making insofar as individuals make default decisions when they are overburdened: a jury is more likely to grant parole in the morning when it is refreshed, and $\mathrm{PhD}$ committee judges act more favorably when they are served food at a dissertation defense. One solution that Ariely offers is to avoid the opportunity for cheating, but he also notes that experiments have shown that in a depleted condition individuals not only have difficulty resisting the temptation to cheat, but also make less effort to avoid such situations. Instead, a good solution might be to succumb to temptation once in a while to avoid depletion (the theory of rational self-indulgence).

After examining individual-level drivers, Ariely moves towards considering the impact of society on cheating behavior. A further determinant in whether individuals cheat is how activities are conditioned by how others and society perceives individual behavior; this phenomenon clarifies the importance of selfsignaling. People appraise themselves according to how they think others see them, a behavior which ultimately shapes their personalities. Ariely argues that fake self-signaling can thus lead to "fake actions" and to a higher level of cheating. One experiment revealed that wearing fake brands negatively affects personality and increases levels of dishonesty (while wearing a genuine product does not increase honesty). Moreover, one small step down the road of dishonesty leads to more slippery steps; failing in just one small thing may lead to the abandonment of a bigger concept as well: cheating thus "evolves" over time with very sharp transitions. When people start to consider themselves cheaters in some minor way, they start acting according this characterization and their morals further loosen. Moreover, this process not only makes the given person less honest, but 
causes them to judge others to be less honest as well. In terms of faking academic credentials, this phenomenon becomes highly relevant: politicians and company leaders may be inclined to be more dishonest. Thus, it is very important to come down on early signs of cheating, and not to disregard it as an activity with no long-term impact.

Ariely continues to reveal the determinants of dishonesty. The next important effect of cheating that he details is self-deception. Experiments show that those who (slightly) cheated on an exam considered themselves capable of scoring higher on a forthcoming exam: the subjects had convinced themselves that their exaggerated performance was their true performance. They also tended to be more "willing" to ignore their failures (i.e. not to reconcile or admit them). The author raises the concerning question whether public acclaim for results created through falsification (and, especially, the receipt of some marker of achievement such as a ribbon, trophy, medal, etc.) cements that fiction. The author emphasizes that although self-deception may boost satisfaction and increase immediate chances of success, it may also build a foundation for bad decision-making and a loss of trust.

Following this argument, Ariely goes into detail about how the human brain creates preferences - which lead to choices - by creating reasons for action. He again confutes the approach that rational action involves following a process of rational decision-making, and rather argues that decisions and actions may be based on gut feelings which individuals later seek to justify (in terms of their rationality) to themselves and to others as well. Measures of brain function support this hypothesis: pathological liars have less grey matter but more white matter (which is responsible for moral judgment) in their prefrontal cortex. This means that such people may have more problems taking morality into account but their association is stronger, which combination may make them perfect liars, good at rationalizing dishonest activities. A separate test also generated the really interesting finding that more creative people were better at coming up with explanations for justifying cheating, although intelligence was not found to correlate to level of cheating. Fostering a creative mindset (for example, by listening to creativity-related words prior to taking action) also enhances dishonest behavior.

After reviewing the activities that impact individuals and their perceptions, Ariely expands the scope again and examines how dishonest behavior may spread and become the norm within an organization. The main goal of the broader project was to help explain the financial crisis of 2008. Ariely hypothesizes that an infection of dishonesty spread throughout certain environments (such as Enron's workplace), upsetting the natural internal balance (for example, through an accumulation of immoral activities that employees experienced around them). 
In one experiment, the majority of people who acted immorally invited others to reassure them that their morals were aligned with those around them. Another experiment witnessed a more-than-doubling of cheating when there was a clearly recognizable cheater in the group. However, when it became obvious to everyone in a following experiment that cheating would have no negative consequences, then the level of cheating level went down, suggesting (again) that it was not rational cost-benefit calculations that drove dishonest behavior, but the collective morality of the environment.

The author then examines the effect of collaboration on individual honesty, because through collaboration benefits may accrue both to individuals and to others, a phenomenon which may trigger altruistic behavior. One of the main reasons for avoiding dishonesty may be the fear of being observed. An experiment strongly supported this hypothesis: when a sign indicating that coffee was available in return for a donation included a picture of eyes observing the likely consumer, three times as much money was collected than when the same sign was decorated with flowers.

An important finding of another experiment (which involved only a slight modification of the basic experiment used previously to test levels and conditions of cheating) is that altruism can increase dishonesty: individuals in the experiment cheated more when the group's benefits depended on their decisions, even when the people in the group were total strangers to each other. What is more, in standard group interactions, even when participants had got to know each other, altruism overpowered supervision and the level of cheating increased. This effect was even stronger when the actor did not personally benefit from their own cheating behavior, as in this case selfishness was totally eliminated and altruism played the major role. Such findings may alter expectations about longterm collaborative efforts when one would expect more honest dealings between provider and client. Medical research shows that the longer a patient-doctor relationship exists, the more it results in benefits to the doctor than practical (i.e. benefitting the patient) healthcare solutions.

In the final chapters Ariely argues that in most cases people seem to be more moral than economic models of risk-benefit would predict. Throughout the experiments few people demonstrated extremely dishonest behavior, and the cost of such was much lower than the cost generated by the huge majority who cheated only slightly. The same experiment was conducted in China, Israel, Turkey, Italy, the United Kingdom and Canada, and the level of cheating was found to be quite similar in every culture.

The 2008 financial crisis can be considered an example of when irrationality had huge impacts, and understanding our shortcomings as decision-makers may help us avoid similar cases in the future. Ariely suggests that we should strive 
to understand which forces impact our behavior, and in which direction, and then discontinue irrational and harmful activities to avoid getting dragged into a vicious cycle: the goal should be to create an end to destructive behaviors, and then a reset.

Ariely argues for the importance of religion which can provide a moral compass, as well as insight into the behavior of individuals, and associated rules (such as the importance of honesty). He observes that several religious texts have strong links to the topic of cheating and share the same findings and even methods in some cases (e.g. the observations that action impacts preferences, favors create loyalty, that conflicts of interest can change perceptions, the need for total honesty, that false witnessing erodes social norms, the need for a clean restart and a recharge of moral energy; that rules help to reduce moral depletion, and that dishonesty may occur for the benefit of others). The key message from this relationship should be that reminders about morals and starting over fresh can make people more honest, and that dishonest behavior should be stopped before it is allowed to happen. 